\title{
Divorce; Albanian reality
}

\author{
Alketa Molla \\ European University of Tirana \\ Faculty : Social Sciences \\ Branch: Sociology, Social Anthropology \\ Email: alketa.molla@Yahoo.com
}

\begin{abstract}
The phenomenon of divorce every day and more is becoming worrisome for Albanian society. Before 90s divorce was taboo. The number of divorced couples was very low and one of the reasons was the mentality, and prejudice build up from the monopoly political system. On the 90 s the political system has changed and we had the phenomenon of the opening of the society and the immigration. Alongside this phenomenon every year it is noticed that the number of divorced couples is been increasing. This phenomenon is documented on the annual statistics provided by courts in the country. The purpose of this study is to explore the impact of the immigration and the opening of the society in to the increasing of the phenomenon of divorce. What kind of background have the couples that had a divorce and how many of these couples have had at least one of the partners in immigration? How much is the impact of the distance between partners in their relationship? What is the level of the presence of the divorce's culture in Albanian reality and what is the impact, influence of the country's culture that Albanian have been immigrated? The improvement of social and economic politics from the government affects the increasing of new jobs, this can make the immigration's phenomenon to be curbed and therefore curbing divorce's phenomenon due to immigration. The study carried out by virtue of representative model. The sample non casual: partners returned from immigration have made the request for divorce. Thematic analysis of data. Conclusions drawn in an interpretative approach. The study will be based on the official data of the courts and data provided by NGOs that have been dealing with divorce.
\end{abstract}

Keywords: Divorce, Divorce culture, migration,marital relationship

\section{Introduction}

Divorce is a human right expressed by law. After 90 s the number of divorces in Albania has been growing. Albania during the mono-party political system was a closed country, isolated and any kind of communication with other countries was avoided. The number of dovorceve was very low because of the mentality, or as a result of the system. In that period, divorce was taboo. It was seen as a very serious act that was accompanied by a series of negative social and psychological consequences for the family members. Albanian society today is an open society. People are able to move, migrate to other countries. Many Albanian families sheltered in emigration. Also many men have emigrated, leaving the family in Albania. The distance for a long time one of the spouses, generally men, accompanied by a range of consequences, including the cooling of relations between spouses. Often this phenomenon creates contradictions and disputes at the couple while the latter led to divorce. Standing for a long time away from each other spouse has brought the creation of new connections in their host country, thus leading to dissolution of marriage. Divorce is portrayed as a social problem of concern to the Albanian reality. The number of Albanian couples divorced has come growing, and recent figures are alarming if they refer to the statistics of the courts. Increasing the number of divorces is evident in major cities and smaller ones. This phenomenon is present throughout society. 


\section{Purpose of the Study}

Divorce is a phenomenon that plagues every day society. This concern comes not only because why has increased but also the fact that he has social as well as economic costs (psychological consequences for partners but also for the children, economic conditions after divorce, etc.).

The purpose of this study is:

Immigration, the opening of the society, as they have increased the number of divorces. How much is present in the Albanian reality the culture of divorce? In this study made a detailed look at the anthropological terms, the impact has been open society, confronting culture in cultures of other countries where Albanians migrated terms of divorce. The study highlights the impact of these other cultures in development of a culture of divorce in Albania.

What are the particular problems that lead a couple to divorce, in terms of relations between spouses and their character? The distance for a long period, has also brought a cooling in the couple keep peace. Couples who previously had their contradictions between the departure of her husband emigrated were added even more these contradictions. Another fact is that the husband emigrated, creates a new connection where it is not concerned with for the family that is left in Albania.

Social and economic changes, their improvement may affect the improvement of conditions in many families. This could possibly bring the curb immigration as a phenomenon, it is known that immigration is so widespread due to the weak economy and the country's high rate of unemployment. Inhibition of migration And downsizi will bring consequently the inhibition of divorce due to immigration.

\section{Questions and Hypothesis}

The hypothesis is cast in this study is:

- Increasing the number of divorces as a result of immigration and the opening of society

Questions posed in this study are:

- What couples go to divorce?

- How many of these couples have had one of the partners in emigration?

- How did the distance for a long time in the relations between them?

- What changes in social policies and cultural and economic will not help these couples divorce?

\section{Methods and Research Methodology}

To realize onwards study used primary data, interviews of divorced persons and secondary data obtained from the literature.

The primary data obtained from interviews conducted with partners who have made them for a divorce are more interested and have the main weight in this study.

They highlight the social problems facing a family with one of the partners in immigration.

In reviewing the literature gathered data relating to divorce that came as a result of leaving for a long time one of the partners in emigration.

The study conducted based on a representative model study with qualitative data collected from the literature. Also in the study included primary data from semi-structured interviews and unstructured that are conducted with the participants in the study.

The sample: Used non-casual approach. Select the champion is aiming to give answers to the study questions. Participants in the study are partners who have made themselves a request for divorce. Interviews were conducted with divorced persons who have stayed away partner for a long time as a result of emigration. The aim of these interviews is to see how it has impacted the distance in the relationship, the pair stay for a long time in one place another culture. 
Data processing is carried out through thematic analysis starting with unprocessed data, interpreting, summarizing and categorizing them.

\section{Conclusions drawn using interpretive approach.}

\section{Analysis, interpretation of data}

Divorce is a social problem which is massive out most recently in Albania. If we refer to the statistics of the major courts in the country the first thing that we would be striking is the fact that every year the number of divorces is incremental. Here we can say that even numbers of marriages per year is high. So therefore there is no marriage divorce. Albanian society is rich with cultural values and norms which apply massively by its members. One of them is the marriage which is a cultural norm that applies generally by all members of society.

If we refer to the statistics of divorce before the 90 th will note that their number is very low, almost negligible. The family has been in the consolidated and partners have had a common lifestyle. We Albanian mentality was the holy family and divorce regarded as taboo as seen as the destruction of the family. This taboo was exacerbated by the communist regime which does not give the individual more freedom and space. He directed not only at individual political views but also his behavior. The influence of politics and family life mentality that many couples do though have contradictions, do not do divorce disputes. Many couples who have problems in their relationships hid them because of the mentality and prejudices that were made by the company. The degree of emancipation of women was very low. They were almost humble before their spouses. There may be thought that women take the initiative to make application for divorce. These are some factors influenced the decrease in the number of divorces during that period. The change of the political system has resulted in the change of mentality regarding marriage, divorce. During the party system in Albanian society there was a culture of divorce and couples stay together even if there were serious problems in their relationships. The strength of opinion, prejudices society had a great impact on them. Political change is accompanied with social changes, increasing the level of independence and secession individual opinion influence his behavior. Increased rate of women's emancipation and awareness for their rights. If at first they do not dare to claim for divorce even if the problems were serious enjoyment, today demand-lawsuits made by numerous women were compared with men. Increasing the number of divorces shows not itself addition of family problems but there are also other means. Dealing Albanian culture with the culture of their host country Albania has had a particular impact in their lives. This has led to the creation of a culture of divorce in Albania which was missing for as long as divorce itself was a taboo couple problems not covered to be agreed by others.

Another factor is the lack of immigration during that system. There was no immigration and thus there was no separate living partners. They lived with each other so the resolve family problems together. There was no unemployment and low economic level was nearly the same for all.

After the change of political system Albanian society faced more veshturesi which were also reflected in family relations. Many people hired in that system emerged now unemployed creating economic problems for their families. Immigration was seen as the only opportunity to ensure their livelihood. The economic difficulties have made many partners to emigrate and live so far from each other. Initially these migrations were carried out illegally by men. They migrating illegally were unable to take along their families. Wives and children stood in Albania. Lack of residency permits in places where they had migrated forcing these valuable partner to stay for a very long time without turning. They came to their families in Albania only in special occasions and stood a few days. This short stay near family so happen because they were employed in places where they had migrated and risk losing their jobs if they do not return in time there. But on the other hand it's prolonged absence accompanied immigrant partner with other family problems that remain to be solved is generally women has led to the deepening of relations between partners cooling. These are coupled with the distance problems that have arisen and are triggered off sharply between these partners. Problems in couples are associated with divorce.

The analysis of data obtained from interviews revile out the fact that during the time that the couple has been living together that have had a normal relationship. $90 \%$ of these cases the couple claim the problems began with the migration of the partner. Largest number of the divorcuarve of what makes couples who have had one of the partners in immigration. But the problem lies not only here. $60 \%$ of divorces are made at the request of women. They complain that upon their return, their spouses have shown bad habits that had not before emigrating. They say that their partners have become violent, aggressive, alcohol users, play games of chance, do not respect them. There are many cases when women accuse their husbands for adultery and fornication for their host countries. This has made these spouses ekonimikisht not contribute to their own families in Albania. In many cases this is the reason that these spouses to make separate application for divorce. 
But there are also other reasons. Physical and psychological violence is a cause that is present in almost all the requirements, lawsuits filed by women. They accuse their wives have committed violence against them. Failure of mutual relations is another cause which negatively affects the couple. The lack of the respect for one another be it even in decisions related to family do you often create friction. Partner does not complete his duties as a parent against requirements and childcare. In some cases women pose as divorce because of the abuse of the household income by the spouses in gambling. The latter not only does not contribute economically to the family itself but also abuse the revenues are mainly provided by spouses.

- $40 \%$ of divorces have come as a result of lawsuits burrave.Kerkese request made by men have as main reasons for divorce adultery and relationships outside of marriage. They complain that at the time of their stay in immigration women would betrayed or worse to have created an affair. Other causes encountered in applications, be they sued for divorce by women or men.

$\cdot$

There are other cases where both partners were immigrants when they made the request for divorce. Difficulties that have faced these couples in their host countries have had a large impact on their relationship. Difficulties to find a job, to adapt to the language and culture of the country where they had migrated had influenced the way they conduct in their Relationship. They argue that problems and disputes began after the couple had emigrated. During the time that had been in Albania couple had a normal relationship.

- From the statistical data, the majority of the divorcuarve are aged 30-40 years old. Partners who belong to this age have had a marriage that lasted mostly more than 5 years. They claim that in the first years of their marriage was normal. Problems between partners started after the birth of children and have increased greatly over the years. Almost all of these marriages have children. There are some cases limited in number, which are almost negligible who have not had children of divorced couples. The study noted that marriage is endangered to an end during the 10 -year-old to her first. The number of divorces is higher for marriages from $5-10$ years. $56 \%$ of the cases studied belong to this category.

The number of divorces that belong partners with age under 30 years old. Most couples divorcuarve you belong to this age do divorce during the first years of marriage without achieving 5-year-old. We request their lawsuits researchers pose as divorce because ignorance best partner because they have made a hasty marriage without a sufficient period of recognition. Regarding the lowest number of divorces it consists of persons who are over 40 years old. Couples who have over 10 years of marriage are less likely to make divorce. It is also noticed by the limited number of divorces performed by these couples compared with those who have less than 10 years martese.44\% of cases have made divorce after having been for more than 10 years married.

From a demographic overview of the distribution of divorces will note that the phenomenon of divorce is more common in urban areas compared to rural areas. Urban areas are those that lead to the highest number of them. $64 \%$ of the divorcuarve are from these areas. They pose the greatest problems of social and economic. Here dominate unemployment, difficult economic situation. Problematic are the vices such as alcohol, gambling which relate mainly to men, especially when they stay away from the family for a long time. Women in urban areas have the highest number of requests for divorce than men. Generally women who have made an application for divorce are employed. Making income from work makes them more secure and independent. Women have become more aware of their rights. So if their marriage has become problematic relationships in pairs are cooled by stay for a long time away partner, being associated with ongoing conflicts and disputes women decide to end the marriage by making separate application for divorce. All women interviewed claimed that they are trying hard to preserve their marriage even for the interests of children but this has been impossible because it has lost its meaning.

Are divorced from rural areas are fewer in number. They constitute $36 \%$ of the divorcuarve. Most of the divorcuarve who have not completed university over belongs to this category. Even these pairs exhibit the same problem in their relationship where dominate conflict, violence and cooling of relations. Number of women who have made an application for divorce from rural areas is lower compared to men. Most women in rural areas are domestic. They care for their family properties and work mainly in agriculture. From this work they provide very little income. Men are mostly immigrant after puthuajse in rural areas is impossible to provide a pune.Rrjedhimisht the problems that have led to divorce these pairs are connected mainly with immigration. There are few cases where both partners were in immigration and one of the partners is back in Albania to make a request for divorce. From interviews emerge data that are specific to couples who are in immigration. Mostly spouses who have migrated away initially and after having secured a permit have made family reunion taking the 
wife emigrated with children. Spouses say that during that stayed away from each other they have had a normal marriage without displaying significant problems. Disputes and contradictions between partners started mainly because they have been united in immigration. Generally women in migration are more likely to make for a divorce if they have a problem in pairs. They say that during their stay far apart they have not noticed their spouses some habits and behaviors which they have emerged after joined in emigration. They allege that stay for a long time only negatively affected their spouses. They have become people with habits that did not have before. From these data it is clear that migration has affected the behavioral change and the addition of family and social problems.

Even literacy rate partners plays an important role in their lives but also in relations in pairs. By inspection of the data obtained from the statistics noted that the large number of divorcuarve mei have not finished secondary education. They constitute $60 \%$ of the divorcuarve. Likewise these people do not have a skill and a steady job. Consequently, their economic incomes are low. This social group constitutes the highest number of emigrants as well have greater difficulty to find jobs in the country. We request-sued for divorce court made the stakeholders present due among other causes economic difficulties that partner not only does not contribute economically to the family but in many cases wastes its revenues in gambling. This category personsh have more disagreements and contradictions with partner. Often conflicts between these partners degenerate into physical violence and psychological.

While the lower number of divorced couples belongs to partners with higher education. Only $6 \%$ of the divorced couples have carried higher education. This I think also the fact that the number of people with higher education who has emigrated is lower. These couples as a reason for divorce submit a mostly adultery and cooling of relationship.

The survey data of the study noted that the number of women seeking divorce is higher than the number of men. This can be explained by the fact that the number of men who emigrated alone without their families is higher than of those who emigrated as a family.

Men are those who exhibit more problems in the family during their migration to non-presence for a long time. Women must cope with family problems. After the partners return from migration many of them exhibit vices and problems which they had not before emigrating. Many women say that life becomes unbearable when economic problems were added to the problems in couple relationships. They claim that it is not easy to make the decision to divorce, especially when children are between .. The breakdown of a marriage may be associated with a variety of negative consequences that have an impact on children as a lack of respect, tolerance for spouses, can also be generate physical and psychological violence.

- From the data obtained in court if he divorces you compare realiuara Arranged marriages are greater in number than those that are made with the mutual consent of the partners so fondly. $52 \%$ of divorces belong arranged marriages

Arranged marriages partners in their request for divorce lawsuits have due among other reasons the mismatch of characters. They claimed that they have known each other well before marriage. As a result of this ignorance their marriage is accompanied by a series of problems and disputes which have degenerated into conflicts during marriage, especially when they have resided for a long time away from each other as a result of immigration.

\section{Conclusions}

As a result of the prolonged transition alongside social problems are also present economic problems. High rate of unemployment, poverty have made many people see immigration as the only possibility to provide them economic income. Emigration from one hand solves economic problems but adds social problems. Solve economic problems because through it many families earn a living tyre.Pra is the only source of immigration on the other hand ardhurave.Por added social problems which have led to an increase in the number of divorceve.Keto problems mainly related to living separate you do partners.

Key factors that play a very important role in family life are social and economic policies in place. These policies directly affect the improvement of living and therefore we iron out the problems in the family. The realization of economic policies would have a wider impact on society. Creation of new jobs would reduce the phenomenon of immigration because it is known that migration takes place mainly for economic reasons. Halting immigration would make you more couples not living separate and so it will not have those problems that cause living away partner. Inhibition of mass immigration would bring the inhibition of divorce was caused by immigration. Government intervention through its social policies and economic factors can significantly affect the reduction of the number of divorces.

Bibliography;

Beqja, Hamit \& Leke Sokol "Divorci- observations and reflections"; 
Tirana Dudaj \& Rinia, Sokol, Leke. Sociological Analysis. Institute of Sociology. Tirana; IS \& Rinia

Articles on divorce published in the press.

Materials and statistics from the organization "Women Forum Elbasan" etc.

Official sources. Statistics from the main courts: Tirana, Elbasan, Fier, Durres, Korca,

Statistical Yearbook of the Ministry of Justice 2009,2010,2011,2012,2013.

Statistics of the "Nation Master", World Statistics.

Ferraro, Garry \& Andreatta, Lusa "Cultural Anthropology, Applied An Prespective"

Belmont, CA: Wadswarth, 2010: 206-283 